\title{
THREE MODELS OF VIBRATING LONG BONES
}

\author{
John Jurist, Ph.D. and Kianpour Kianian, B.S. \\ Division of Orthopedic Surgery Internal Report \\ University of Wisconsin Medical Center \\ Madison, Wisconsin 53706
}

\section{MODEL I}

\section{INTRODUCTION}

Previous papers have reported the ulnar resonant frequencles of normal subjects and of various patient populations $[5-7,9]$. As a conceptual model for these studies, the ulna was treated as a cylindrical tube attached to rigid supports at each end by hinges which simulate the joints. This report evaluates the ability of the model to predict the ulnar resonant frequency of patients for whom the ulnar length was measured and for whom the ulnar mineral content and width was determined at a specific location by the photon absorptiometric method [11].

THEORY

The ulna is considered to be a uniform cylindrical tube of length $L$, outside diameter $2 a_{p}$, and inside diameter $2 a_{e}$ (Fig. 1). The tube is attached at each end to rigid supports by hinges which allow deflection in the $x-y$ plane only (Fig. 2). The material of which the tube is composed is treated as a homogeneous, isotropic substance of density $\rho$ with a Young's modulus of elasticity of $Y$.

It can be shown [8] that the transverse deflection y from the equilibrium position at a location $x$ along the axis of the vibrating tube is given by

$$
y=\cos (\omega t+\varphi)[A \cosh (\omega x / v)+B \sinh (\omega x / v)+C \cos (\omega x / v)+D \sin (\omega x / v)] .
$$

In this equation, $w$ is the angular frequency of vibration, is time, $\varphi$ is an arbitrary epoch, and $v$ is the phase velocity of the transverse wave component with angular frequency $\omega$ along the length of the tube. $A, B, C$, and $D$ are arbitrary constants determined from boundary conditions. The phase velocity is given by

(2) $v=\sqrt{\omega \mathrm{CK}}$,

where $c$ is the speed of longltudinal wave propagation through the 


\section{DISCLAIMER}

This report was prepared as an account of work sponsored by an agency of the United States Government. Neither the United States Government nor any agency Thereof, nor any of their employees, makes any warranty, express or implied, or assumes any legal liability or responsibility for the accuracy, completeness, or usefulness of any information, apparatus, product, or process disclosed, or represents that its use would not infringe privately owned rights. Reference herein to any specific commercial product, process, or service by trade name, trademark, manufacturer, or otherwise does not necessarily constitute or imply its endorsement, recommendation, or favoring by the United States Government or any agency thereof. The views and opinions of authors expressed herein do not necessarily state or reflect those of the United States Government or any agency thereof. 


\section{DISCLAIMER}

Portions of this document may be illegible in electronic image products. Images are produced from the best available original document. 
material of the tube and $K$ is the radius of gyration of the cross section of the tube about the neutral axis. The speed of longitudinal wave propagation is given by

(3) $c=\sqrt{Y / P}$,

and the radius of gyration is given by

(4) $k=0.5 \sqrt{a_{p}^{2}+a_{e}^{2}}$.

The angular frequency of vibration $(\omega)$ is related to the cyclic frequency of vibration ( $f$ ) by

(5) $\omega=2 \pi f$.

At each end of the hinged bar, the displacement and internal moment must vanish [8]. Therefore,

(6) $y=0$ and (7) $\frac{\partial^{2} y}{\partial x^{2}}=0 \quad$ at $x=0$ and $x=1$.

Substitution of Equation 1 into Equations 6 and 7 at $x=0$ and simplifying shows that the constants $A$ and $C$ vanish. Therefore,

(8) $y=\cos (\omega t+\varphi)[B \sinh (\omega x / v)+D \sin (\omega x / v)]$.

Substitution of Equation 8 into Equations 6 and 7 at $x=L$, eliminating sinh(wL/v) and simplifying yields

(9) $\quad \sin (\omega \mathrm{L} / v)=0$.

The fundamental nontrivial solution of Equation 9 is

(10) $\omega_{0} L=\pi v$,

where $\omega_{0}$ is the allowed angular frequency of vibration. If $f_{0}$ is defined as the allowed cyclic frequency of vibration,

(i1) $f_{0}=\frac{\pi c}{4 L^{2}} \sqrt{a_{p}^{a}+a_{e}^{2}}$

is obtained by combining Equations 2, 4, 5, and 10 and then simpli.fying. Equation 11 forms the basis for predicting ulnar resonant frequency given $L, M_{B}$, and $W_{1} M_{B}$ and $W$ are the mineral content (expressed in $\mathrm{g} / \mathrm{cm}$ ) and width (expressed in $\mathrm{cm}$ ) of the ulna at a scan site proximal to the ulnar head by $0.3 \mathrm{~L}$. It is assumed that this location provides a representative cross section of the ulna (Fig. 3). 
From experimental data relating ash content to density of compact bone $[10]$, one finds that

$$
b=1.1806 p-1.1945 \text {, }
$$

where $b$ is the ash or mineral content (expressed in $\mathrm{g} / \mathrm{cm}^{3}$ ) of fresh cortical bone. If Equation 12 is multiplied by the cross sectional area of the bone, one finds that, since

$$
M_{B}=\pi b\left(a_{p}^{2}-a_{e}^{2}\right)
$$

$$
M_{B}=\pi\left(a_{p}^{2}-a_{e}^{2}\right)(1.1806 p-1.1945) .
$$
Since the width of the bone at the scan site (W) is given by $2 a_{p}$,
one may solve Equation 14 for $a_{e}^{2}$, combine the result with

Equation 11, substitute the expression for $W$, and simplify:

$$
f_{0}=\frac{\pi c}{4 L^{2}} \sqrt{\frac{W^{3}}{2}-\frac{M_{B}}{\pi(1.1806 p-1.1945)}} .
$$

Experimental measurements of $c, \rho$, and $Y$ in excised strips of fresh cortical bone [1] allow one to derfve (in cgs units)

$$
c=2.1427 \cdot 10^{5}+6.5333 \cdot 10^{-7} Y, \quad \text { and }(17) \quad p=1.2586+3.6429 \cdot 10^{-12} Y \text {. }
$$

If these equations are substituted into Equation 15 and the result simplified, one obtains

$$
f_{0}=\frac{\pi}{4 L^{2}}\left(a_{1}+b_{2} Y\right) \sqrt{\frac{W^{2}}{2}-\frac{M_{B}}{\pi\left(a_{2}+b_{2} Y\right)}},
$$

where $a_{1}=2.1427 \cdot 10^{5}$, and $b_{2}=4.3008 \cdot 10^{-12}$. Equation 18 can be used in efther of 2 ways. First, it can be used to determine the value of $f_{0}$ predicted by the model given $L, M_{B}$, and $W$. In this case, some accepted mean value of $Y$ must be used. Then, the predicted value of $f_{0}$ can be compared to the measured value of this parameter. Second, Equation 18 can be used to determine the value of $Y$ predicted by the model given the values of $\mathrm{f}_{O}, L, M_{B}$, and $W$.

METHOD AND RESULTS

A group of 118 schoolchildren, ranging in age from 6 to 11 years, was selected. for this study. First, assuming a constant Young's 
modulus of $1.6865 \cdot 10^{11}[1]$, and given $L, W$, and $M_{B}$ for each child, Equation 18 was used to predict $f_{0}$ : The predicted $f_{0}$ values are plotted against the measured values in F1g. 4. Second, Equation 18 was rearranged to obtaln a third order polynomial expression for $Y$ :

$$
A_{1} Y^{3}+A_{3} Y^{2}+A_{3} Y+B=0
$$

where $A_{1}=\pi^{2} W^{2} b_{1}^{a} b_{2}, \quad A_{2}=\pi^{2} w^{2} b_{1}^{2} a_{2}+2 \pi^{2} w^{2} b_{1} b_{2} a_{1}-2 \pi M_{B} b_{2}^{2}$,

$A_{3}=2 \pi^{2} W^{2} b_{1} a_{2} a_{2}+\pi^{2} W^{2} b_{2} a_{1}^{3}-4 \pi M_{B} b_{1} a_{2}-32 f_{0}^{3} b_{2} L^{4}$, and

$B=\pi^{2} W^{2} a_{1}^{2} a_{2}-2 \pi M_{B} a_{1}^{2}-32 f_{0}^{2} a_{2} L^{4}$.

This cubic was solved by a standard formula which ylelds only the real root(s). The values of $Y$ which are obtained by solution of Equation 19 are plotted as a function of age for the schoolchildren in Fig. 5. The RMS values (root mean square of the percentage discrepancies of the predicted values in terms of the actual values) of resonant frequency and Young' $s$ modulus are rather large. This suggests that either the uncertainty in the experimentally measured quantities caused poor behavior of the model, or the model itself is not applicable.

The calculated value of Young's modulus based on this model was determined for each member of the 6 patient populations described in Table I. Figs. 6-11 show the predicted $Y$ values as a function of age for these groups.

ERROR ANALYSIS

For an analytic function $y$, where $y=y\left(x_{1}, x_{2}, x_{3}, \ldots\right)$ with uncertainties of $\Delta x_{1}, \Delta x_{3}, \Delta x_{3}$, etc. associated with $x_{1}, x_{2}, x_{3}$, etc., respectively, the uncertainty $\Delta y$ in $y$ is given by

$\Delta y=y \sqrt{\left(\frac{\partial y}{\partial x_{1}} \cdot \frac{\Delta x_{1}}{y}\right)^{2}+\left(\frac{\partial y}{\partial x_{2}} \cdot \frac{\Delta x_{2}}{y}\right)^{2}+\left(\frac{\partial y}{\partial x_{3}} \cdot \frac{\Delta x_{3}}{y}\right)^{3}+\ldots} \cdot$

In order to estimate the uncertainty of $f_{0}$ and $Y$ associated with the model, we calculated $\Delta \mathrm{f}_{\mathrm{o}}$ and $\Delta \mathrm{Y}$ using data for a typical subject: $M_{B}=0.80 \pm 0.05 \mathrm{~g} / \mathrm{cm}$ (uncertainty 6.3\%), $W=1.00 \pm 0.10 \mathrm{~cm}$ (uncertainty 10.0\%), 
$L=25 \pm 1 \mathrm{~cm}$ (uncertainty $4.0 \%$ ), and $Y=1.6865 \cdot 10^{11} \pm 1.6865 \cdot 10^{10} \mathrm{dynes} / \mathrm{cm}^{2}$ (uncertainty $10.0 \%$ ) . The predicted value of the resonant frequency 18 then $f_{0}=204 \pm 47 \mathrm{~Hz}$ (uncertainty $23 \%$ ). Similarly, the uncertainty In $Y$ was calculated using the same assumed values and uncertainties for $M_{B}, W$, and $L$. If the measured $f_{0}$ is assumed to be $204 \pm 10 \mathrm{~Hz}(5 \%)$, then the calculated value of Youngs modulus is found to be $1.6865 \cdot 10^{11} \pm 1.4323 \cdot 10^{10}$ dynes $/ \mathrm{cm}^{2}(8.5 \%)$. These calculations clearly demonstrate that a small uncertainty in Young's modulus introduces a larger uncertainty in the resonant frequency predicted by the model.

\section{MODEL II}

\section{INTRODUCTION}

This model simulates the flexural vibration of a beam which is hinged at each end and is supported along its length by an elastic foundation. This model is similar to Model I except for the addition of the elastic foundation which simulates the elastic properties of the soft tissue (mostly muscle) which surrounds the ulna. Conceptually, this model is a better approximation of the vibrating ulna than is Model I, but it is not satisfactory for several inherent reasons.

\section{THEORY}

Consider the beam shown in Fig. 12. For the first and second mode of vibration, the deflection curve may be approximated by

(20) $y=\alpha_{n} \sin (n \pi x / L)$, where

(21) $\alpha_{n}=\alpha_{0} \sin \left(\omega_{n} t\right)$.

The kinetic $\left(E_{k}\right)$ and potential $\left(E_{p}\right)$ energy of the vibrating bar may be written as

$$
E_{k}=\frac{M}{2 L} \int_{0}^{L}\left(\frac{\partial y}{\partial t}\right)^{2} d x \text {, and }
$$

$$
E_{p}=\frac{Y I}{2} \int_{0}^{L}\left(\frac{\partial^{2} y}{\partial x^{2}}\right)^{2} d x+\frac{k}{2 L} \int_{0}^{L} y^{a} d x,
$$

respectively. In these equations, $M$ is the mass of the bar, I is the moment of inertia of the cross section of the bar, and $k$ is the spring constant of the foundation (soft tissue). By substitution of the proper derivatives into Equations 22 and 23, one can maximize $E_{k}$ and $E_{p}$ to obtain

(24) $E_{k_{\max }}=0.25 \mathrm{MN} \alpha_{n}^{2} \alpha^{2}$, and (25) $\mathrm{E}_{\mathrm{P}_{\max }}=\frac{\alpha^{2}}{4}\left(\mathrm{~K}+\mathrm{YIn} \mathrm{In}^{4} / \mathrm{L}^{3}\right)$. 
Equating $E_{k}$ and $E_{p_{\max }}$ ylelds the nondimensional equation

$$
\omega_{n}^{2}=Y I \frac{(n \pi)^{4}}{M I^{3}}+\frac{k}{M}
$$

In Equation 26, $n$ has allowed values of 0,1 , or 2 . It can be shown that

$$
\text { (27) } M=M_{B} L \rho / b \text {, and }
$$$$
\text { (28) } I=\frac{M_{B}}{2 b}\left(\frac{W^{2}}{2}-\frac{M_{B}}{\pi b}\right) \text {. }
$$

In order to obtain an estimate of $k$, the foundation spring constant, we assume that the bone is surrounded by a muscle-like material of thickness $2.5 \mathrm{~cm}$ and Young's modulus of 52,000 dynes/ $\mathrm{cm}^{2}$ [3]. W1th this assumption, one finds that

$$
k=4.15 \cdot 10^{4} \mathrm{LW} \text {. }
$$

By substituting Equations 27-29 into Equation 26 for $n=1$, one can calculate the allowed frequency of vibration.

\section{RESULTS}

This model was tested. with the same data as was used for Model I. In general, the predicted resonant frequencles were larger than for the first model. This is predominantly a result of the term $\mathrm{k} / \mathrm{M}$ in Equation 26 (representing the foundation or soft tissue elasticity).

There are 2 additional difficulties with this model. First, the approximation that is made for the flexural deflection is not easily justified. Second, using the exact expression of flexural deflection for solving the equations of motion for the model is so difficult as to be impractical.

\section{INTRODUCTION}

\section{MODEL III}

The previous models were inadequate in some respects. Thus, we evaluated a third model which assumes that the vibrating bar is attached to rigid supports by springs rather than hinges at each end. These springs simulate the elastic properties of the articular cartilage found at each end of the ulna.

\section{THEORY}

The only difference between this model and Model I is the change in boundary conditions. The force constants of the 2 springs are $K_{e}$ and $K_{w}$ for the "elbow" and "wrist". respectively. Fig. 13

illustrates this model. 
At each end of the bar, the internal moment vanishes. Thus, (30) $\frac{\partial^{3} y}{\partial x^{2}}=0 \quad$ at $x=0$ and $x=L$.

Substitution of Equation 1 into Equation 30 at $x=0$ and simplifying shows that

(31) $\mathrm{A}=\mathrm{C}$.

Substitution of Equation 31 into Equation 1 and substitution of the result into Equation 30 at $x=L$ and simplifying yields

$$
D=A \frac{\cosh (\omega L / v)-\cos (\omega L / v)}{\sin (\omega L / v)}+B \frac{\sinh (\omega / / v)}{\sin (\omega L / v)}
$$

Therefore,

(33) $y=\cos (\omega t+\varphi)\left[A\left\{\cosh (\omega x / v)+\cos (\omega x / v)+\frac{\sin (\omega x / v)}{\sin (\omega L / v)}[\cosh (\omega L / v)-\cos (\omega L / v)]\right\}\right.$

$$
\left.+B\left\{\sinh (\omega x / v)+\frac{\sin (\omega x / v)}{\sin (\omega L / v)} \sinh (\omega i / v)\right\}\right] \text {. }
$$

Also, it can be shown that the elastic force [8] is

(34) $K_{e} y=\left(a_{p}^{4}-a_{e}^{4}\right) \frac{\pi Y}{4} \frac{\partial^{3} y}{\partial x^{3}}$ and

(35) $K_{w} y=-\left(a_{p}^{4}-a_{e}^{4}\right) \frac{\pi Y}{4} \frac{\partial^{3} y}{\partial x^{3}}$

at $x=0$ and $x=L$, respectively. Substitution of Equation 33 into Equations 34 and 35 , combining and simplifying the result yields

$$
\frac{8 \mathrm{~K}_{\mathrm{w}}}{\pi Y \alpha_{1} X^{3}}\left(\sinh (X L)-\frac{\alpha_{2} \cosh (X L)}{\alpha_{3}-\alpha_{5}}\right)=\cot (X L) \sinh (X L)-\cosh (X L)+\frac{\alpha_{2} \alpha_{4}}{\alpha_{3}-\alpha_{5}},
$$

where

(37) $\mathrm{X}=\omega / \mathrm{v}$,

(38) $\alpha_{2}=a_{p}^{4}-a_{e}^{4}$,

(39) $\alpha_{2}=\sin (X i)-\sinh (X L)$,

(40) $\alpha_{3}=\cos (X L)-\cosh (X L)$,

(41) $\alpha_{4}=\alpha_{3} \cot (X L)+\sin (X L)+\sinh (X I)$, and

(42) $\alpha_{5}=8 \mathrm{~K} \mathrm{e}^{\sin (\mathrm{XL}) /\left(\pi \mathrm{Y} \gamma_{1} \mathrm{X}^{3}\right)}$.

As for the case of Model I, the variables in Equation 36 may be expressed in terms of $W, L, M_{B}, Y, f_{0}$, etc. Young's modulus of 
cartilage was derived from the literature [2] $\left(3.385 \cdot 10^{8}\right.$ dynes $\left./ \mathrm{cm}^{2}\right)$. Based on the assumption that the articular cartilage is 2 um thick at both wrist and elbow, and that the bearing surface $1 \mathrm{~s} 2 \mathrm{~cm}^{2}$ and $1 \mathrm{~cm}^{2}$ at the elbow and wrist, respectively, $K_{e}$ and $K_{w}$ were estimated to: have values of

(43) $K_{e}=6.78 \cdot 10^{9}$ dynes $/ \mathrm{cm}$, and

(44) $K_{w}=1.69 \cdot 10^{9} \mathrm{dynes} / \mathrm{cm}$.

In order to calculate the resonant frequency of. the ulna based on this model, one must solve Equation 36 for $X$ or $\omega / v$. Unfortunately, there is no explicit solution of the function

$$
X=X\left(Y, L, W, M_{B}, K_{e}, K_{W}\right) \text {. }
$$

Therefore, one must solve this function numerically with a digital computer. This function was initially solved by Newton's method [4], but the convergence was too slow. We then used $\Delta^{3}$-Aitken's accelerating method. This improved convergence markedly.

A typical plot of Equation 36. is shown in Fig. 14. The resonant frequency predicted by the model can be found from the value of $X$ where the left hand side (LHS) and right hand side (RHS) of Equation 36 intersect. The fundamental resonance is obtained from the lowest value of $X$ at intersection if several intersections occur. In Fig. 14, the first intersection occurs at $X \cong 0.13$.

\section{RESULTS}

Generally, this model is similar to the hinged-hinged model (see Fig. 15). One expects Models I and III to yield increasingly similar results as the values of $\mathrm{K}_{e}$ and $\mathrm{K}_{\mathrm{w}}$ increase. Experimentally, this was shown to be the case. The behavior of the model is quite satisfactory for realistic values of $K_{e}$ and $K_{w}$. At first, this model was compared to Model I on the basis of the data collected from the schoolchildren. Initially, the RMS of frequency was $10 \%$ larger for Model III than for Model I. However, by systematically changing. $W$, $M_{B}, K_{e}$, and $K_{w}$, we were able to force a marked improvement in RMS of predicted frequency. Table II summarizes the behavior of Model III as the parameters mentioned above were changed.

From the above, it is apparent that the predicted resonant frequency based on this model is largely dependent on bone width and is not critically dependent on the other parameters. As mentioned carlier, we assumed that $W$ at the standard $0.3 \mathrm{~L}$ scan site represented an average width for the ulna. However, this assumption may not be valid. 
We found that using $1.1 \mathrm{~W}$ instead of $W$ in the model improved the RMS of frequency (Fig. 16).

\section{DISCUSSION}

Model I and Model III were also compared for several patient populations. Our findings are summarized in Table III. From this table, one can see that the spring-spring model (Model III) more accurately predicts resonant frequency than does the hinge-hinge model (Model I), but this fit is still far from ideal. This by no means implies that the model is invalid, but may be a result of the rather large uncertainty in some of the measured variables. For example, as we have seen previously, the uncertainty in the average width measurement of the ulna introduces a large uncertainty in the predicted frequency of ulnar resonance ( $E_{0}$ is critically dependent on $\mathrm{W})$.

Based on the above analysis, a better model can be proposed that is independent of $W$. This model would be essentially a spring-spring model like Model III, but a truncated conical bar or tube would be substituted for the cylindrical bar. This proposed model would more closely approximate the anatomical shape of the ulna, but has the disadvantage that one must know the width of the bone at 2 different scan sites in order to completely define the dimensions of the bar. Theoretically, we can then expect a better resonant frequency approximation to the measured frequency of ulnar resonance.

\section{REFERENCES}

1.W. Abendschein, G. Hyatt: Clin. Orthop. 69:294, 1970.

2. F. Evans, H. Lissner: P. 4 in The Seventh Stapp Car Crash Conference Proceedings, Springfield, I11:, Thomas, 1965.

3. P. Honcke: Acta Physiol. Scand. Supp. 48, 1947.

4. E. Isaacson, H. Keller: P. 97,108 in Analysis of Numerical Methods, New York, Wiley, 1966.

5. J. Jurist: Phys. Med. Biol. 15:417, 1970.

6. J. Jurist: Phys. Med. Biol. 15:427, 1970.

7. J. Jurist: .p. 68 in Proceedings of Bone Measurement Conference, AEC Conf-700515, 1970 .

8. L. Kinsler, A. Frey: p. 64 in Fundamentals of Acoustics, New York, Wiley, 1950.

9. M. Mueller, J. Cameron, J. Jurist: p. 405 in Proceedings of Bone 
Measurement Conference, AEC Conf-700515, 1970.

10. R. Robinson: p. 186 in Bone as a Tissue, New York, McGraw-H111, 1960.

11. J. Sorenson, J. Cameron: J. Bone Jt. Surg: 49A:481, 1967.

TABLE I

Clinical Groups Evaluated

SEX CLINICAI DESCRIPTION OF GROUP

$M$

Normal

Normal

\# IN GROUP

F

Rheumatoid Arthritis Without Steroids

91

97

17.

Rheumatoid Arthritis Without Steroids

39

Rheumatold Arthritis With Steroids

Rheumatold Arthritis With Steroids

11

34

\section{TABLE II}

Effect of Parameter Variation on Frequency RMS for Schoolchildren

\section{PARAMETER(S)}

$K_{e}, K_{w}$

$\mathrm{K}_{\mathrm{e}}, \mathrm{K}_{\mathrm{w}}$

$M_{B}$

W

$M_{B}, W$

$M_{B}, W$

$\mathrm{W}, \mathrm{Y}^{*}$
CHANGE

$+13 \%$

$-20 \%$

$+15 \%$

$+10 \%$

$+15,10 \%$

$-15,+10 \%$

$+10 \%$

CHANGE IN RMS

$-1 \%$

$+3 \%$

$+9 \%$

$-16 \%$

$+4 \%$

$+1 \%$

$-13 \%$

H

corrected for age based on Fig. 5 . 
TABLE III

Rellabllity of Resonant Frequency Prediction

\begin{tabular}{|c|c|}
\hline SEX & GROUP \\
\hline$M+F$ & Schoolch1ldren \\
\hline F & $\begin{array}{l}\text { No Rheumatoid Arthritis } \\
\text { No Steroids } \\
\text { No Osteoporosis }\end{array}$ \\
\hline $\mathbf{P}$ & $\begin{array}{l}\text { Rheumatoid Arthritis } \\
\text { No Steroids }\end{array}$ \\
\hline $\mathbf{F}$ & $\begin{array}{l}\text { Rheumatoid Arthritis } \\
\text { With Steroids }\end{array}$ \\
\hline $\mathbf{M}$ & $\begin{array}{l}\text { No Rheumatoid Arthritis } \\
\text { No Steroids } \\
\text { No Osteoporosis }\end{array}$ \\
\hline $\mathbf{M}$ & $\begin{array}{l}\text { Rheumatoid Arthritis } \\
\text { No Steroids }\end{array}$ \\
\hline M & $\begin{array}{l}\text { Rheumatoid Arthritis } \\
\text { With Steroids }\end{array}$ \\
\hline $\mathbf{F}$ & $\begin{array}{l}\text { No Rheumatoid Arthritis } \\
\text { With Steroids }\end{array}$ \\
\hline M & $\begin{array}{l}\text { No Rheumatoid Arthritis } \\
\text { With Steroids }\end{array}$ \\
\hline F & $\begin{array}{l}\text { No Rheumatold Arthritis } \\
\text { No Sterolds } \\
\text { W1 th Osteoporosis }\end{array}$ \\
\hline
\end{tabular}

\begin{tabular}{|c|c|c|c|}
\hline & $\bar{W}$ & & IW \\
\hline 非 & RMS & 非 & RMS \\
\hline 118 & 19.249 & 118 & 23.300 \\
\hline 41 & 28.410 & 41 & 35.700 \\
\hline
\end{tabular}

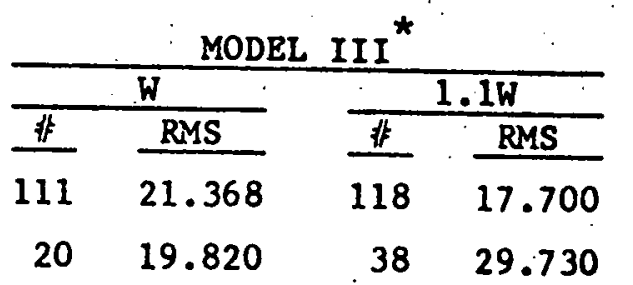

$\begin{array}{rrrrrrrrr}39 & 33.883 & 39 & 36.700 & 18 & 26.092 & 31 & 32.360 \\ 34 & 47.299 & 34 & 58.300 & 21 & 42.090 & 28 & 46.900 \\ 29 & 25.949 & 28 & 26.000 & 20 & 29.038 & 28 & 20.700\end{array}$

$\begin{array}{llllllll}17 & 28.840 & 17 & 35.800 & 13 & 222.640 & 17 & 45.200\end{array}$

$\begin{array}{llllllll}11 & 30.782 & 11 & 38.800 & 7 & 32.628 & 11 & 31.100\end{array}$

$\begin{array}{llllllll}9 & 28.440 & 9 & 38.700 & 6 & 24.737 & 9 & 28.700\end{array}$

$\begin{array}{lllllllll}4 & 25.153 & 5 & 31.600 & 3 & 29.683 & 4 & 24.500\end{array}$

$\begin{array}{llllllll}6 & 33.459 & 6 & 49.500 & 6 & 25.200 & 6 & 34.300\end{array}$

* When Model III was used for the Schoolch1ldren whth $1.1 \mathrm{~W}$ and with $Y$ corrected for age, the RMS of 

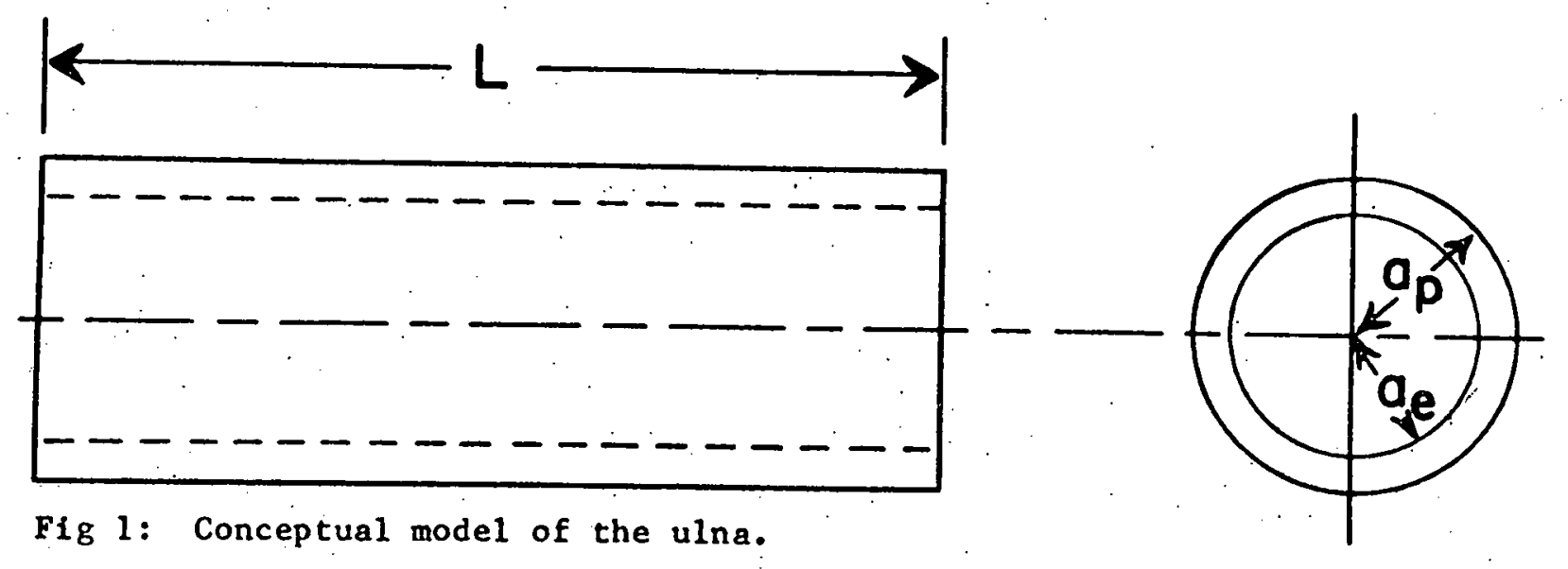

Fig 1: Conceptual model of the ulna.

\section{$y$ axis}

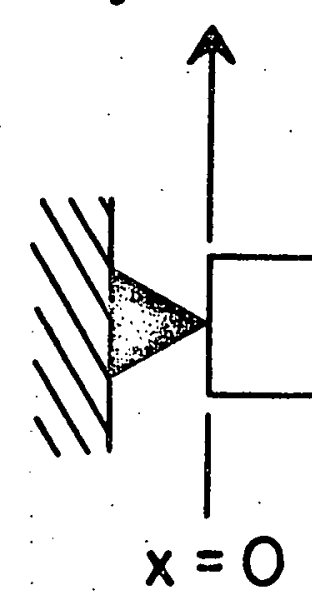

Fig 2: Model I boundary conditions.
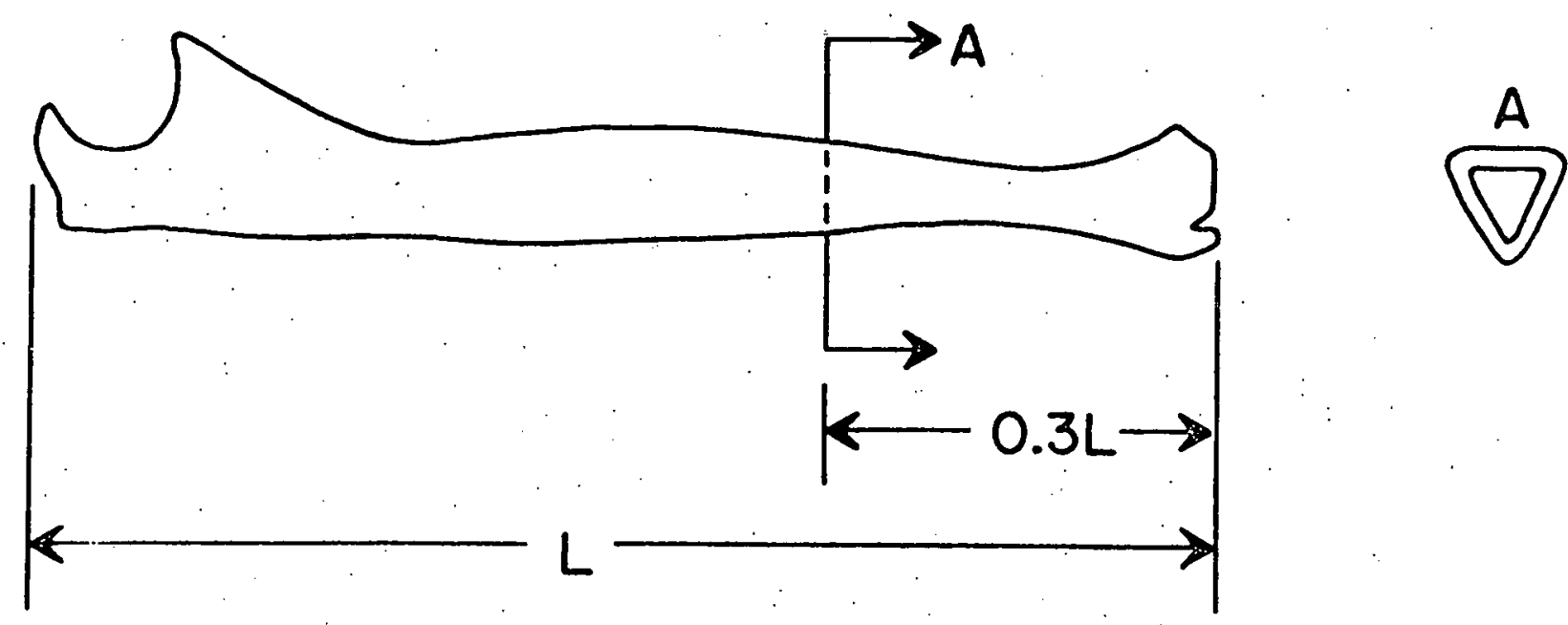

Fig 3: Absorptiometric scan site location. 


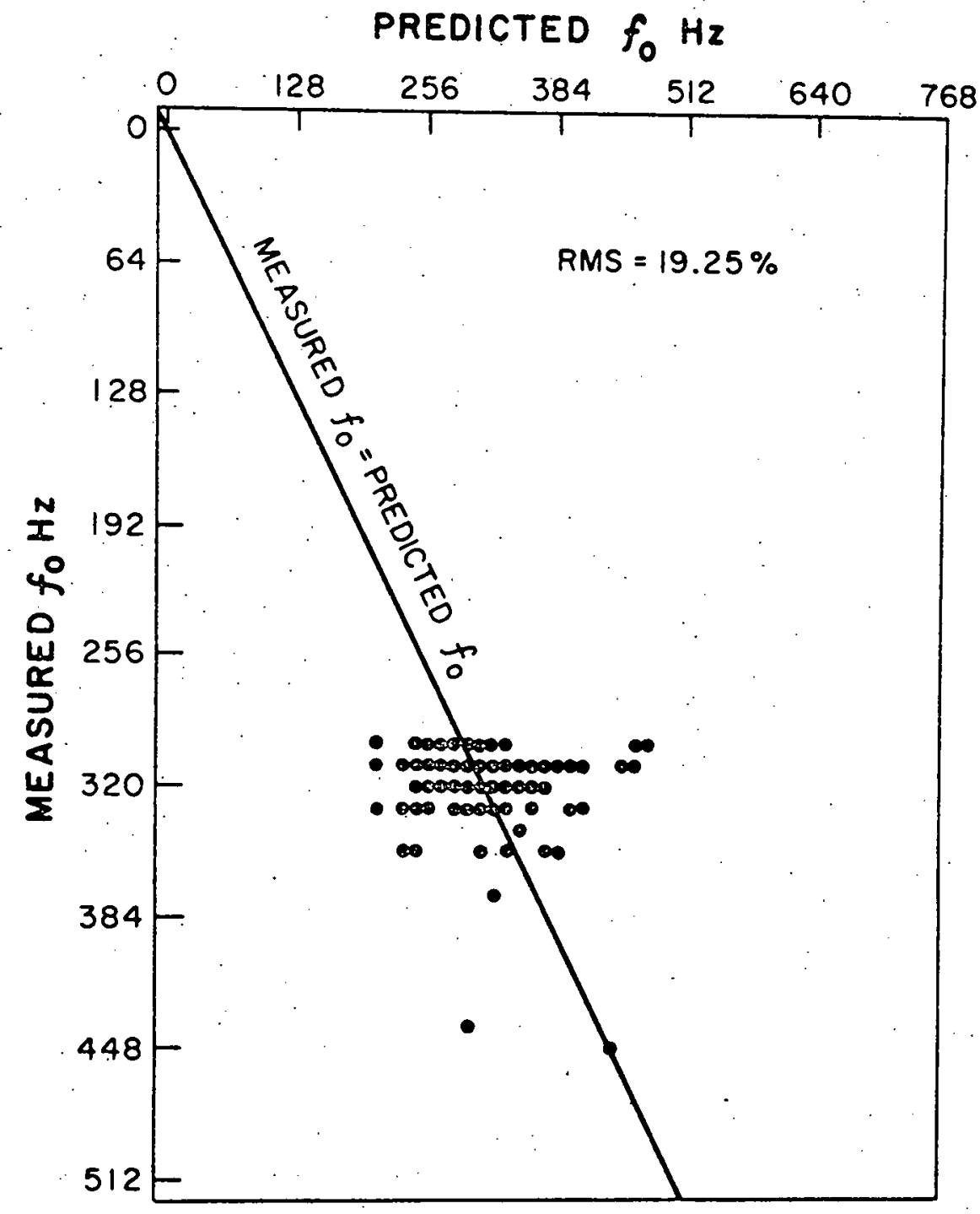

Fig 4: Predicted $f_{0}$ vs measured $f_{0}$ based on Model $I$ for 118 schoolchildren. The RMS value (root mean square of the percentage discrepancy of predicted $f_{0}$ in terms of the measured $f_{0}$ ) $1 \mathrm{~s} 19.25 \%$.

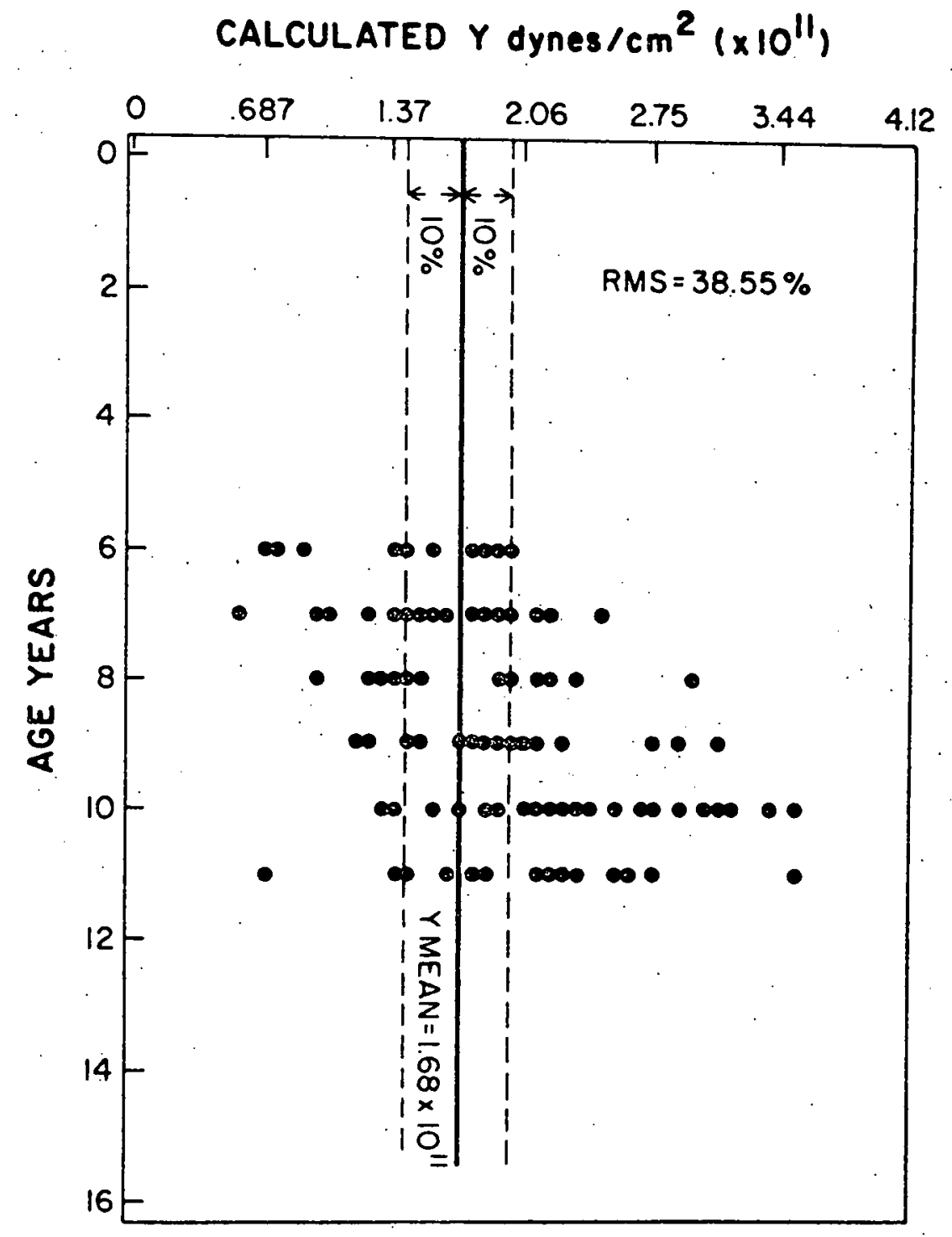

Fig 5: Calculated $Y$ vs age based on Model I for 118 schoolchildren. 


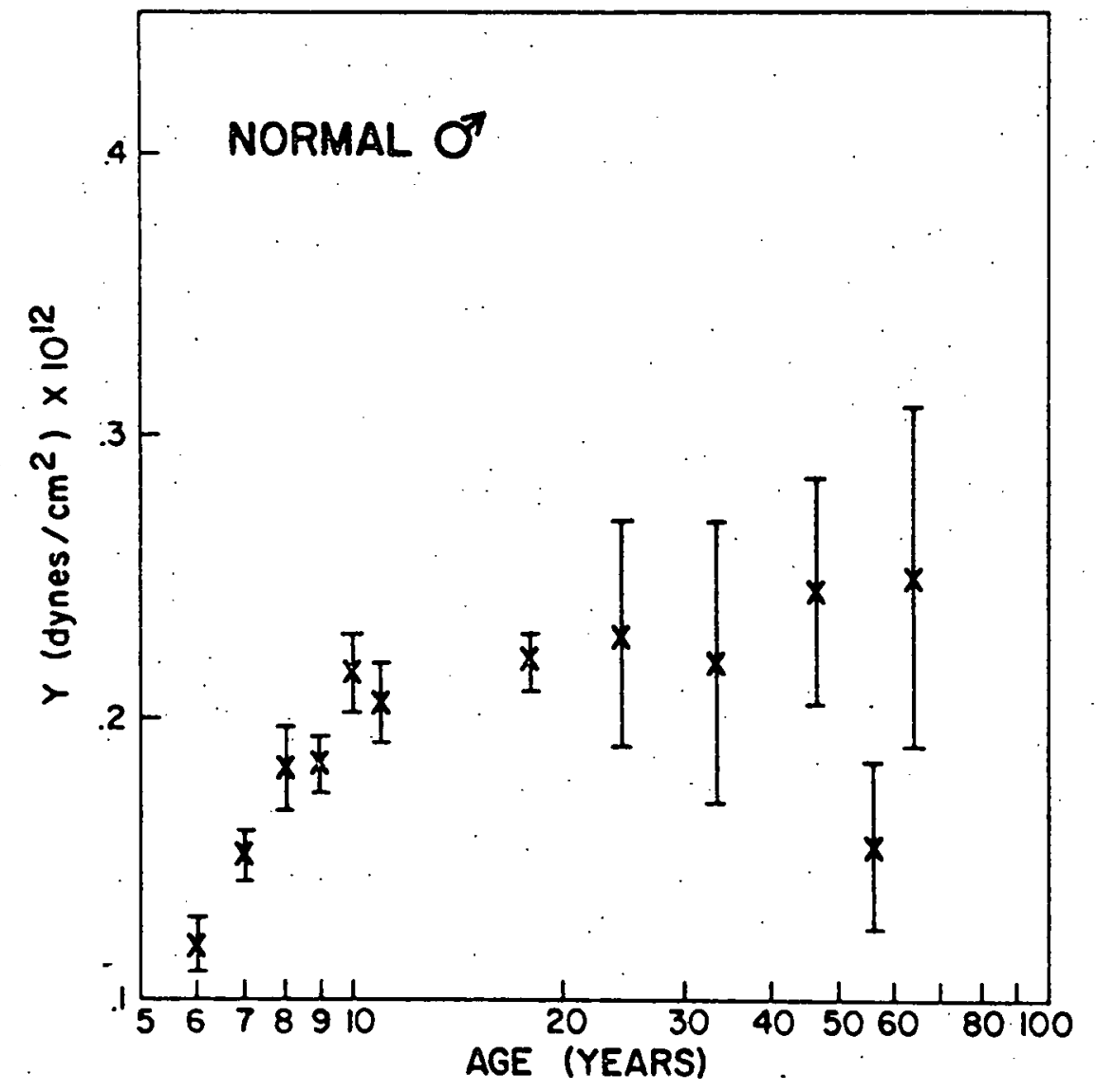

Fig 6: $Y$ vs age for 91 normal male subjects. The range bars enclose \pm 1 standard error of the mean.

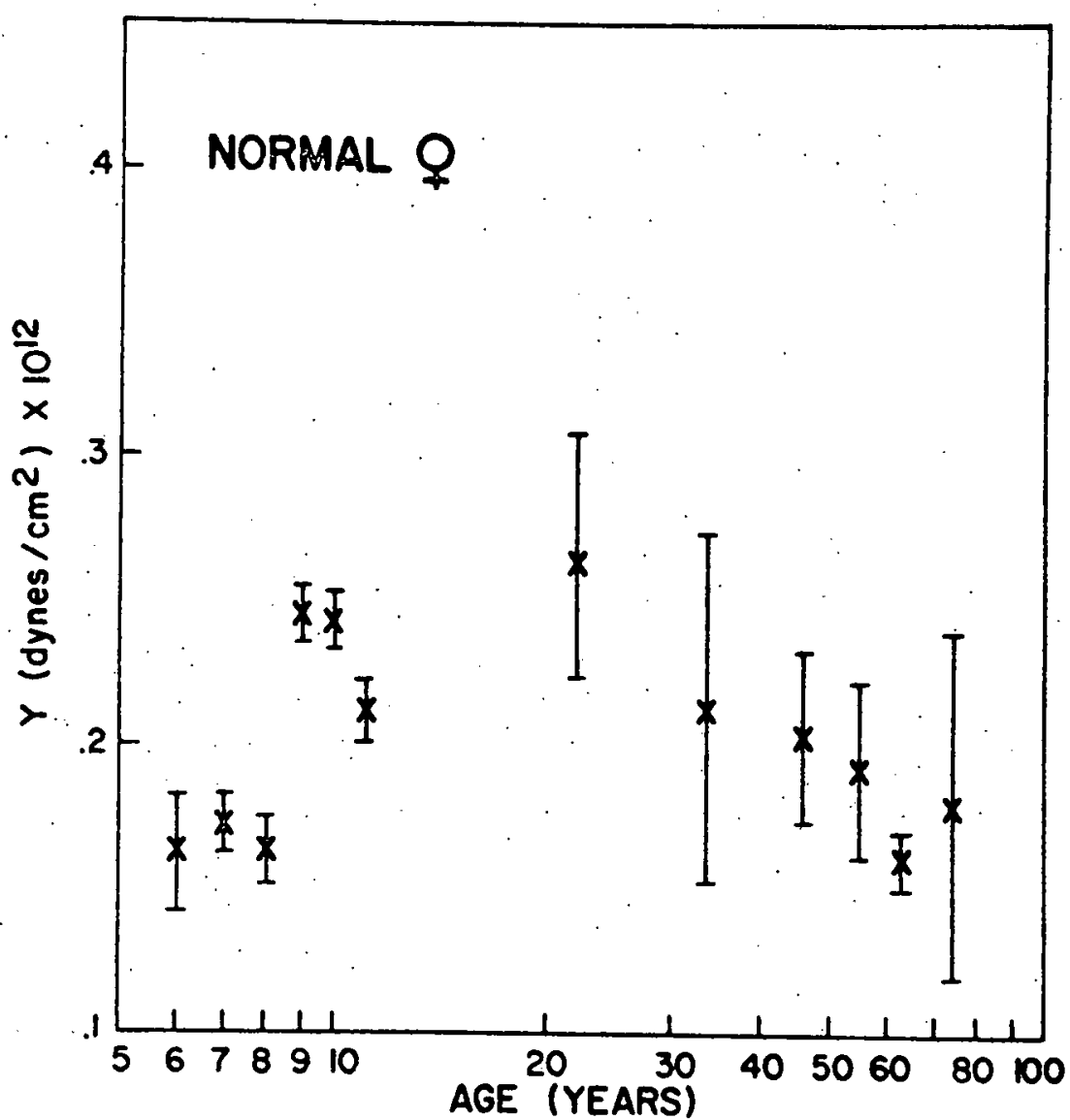

Fig 7: Y vs age for 97 normal female subjects. 


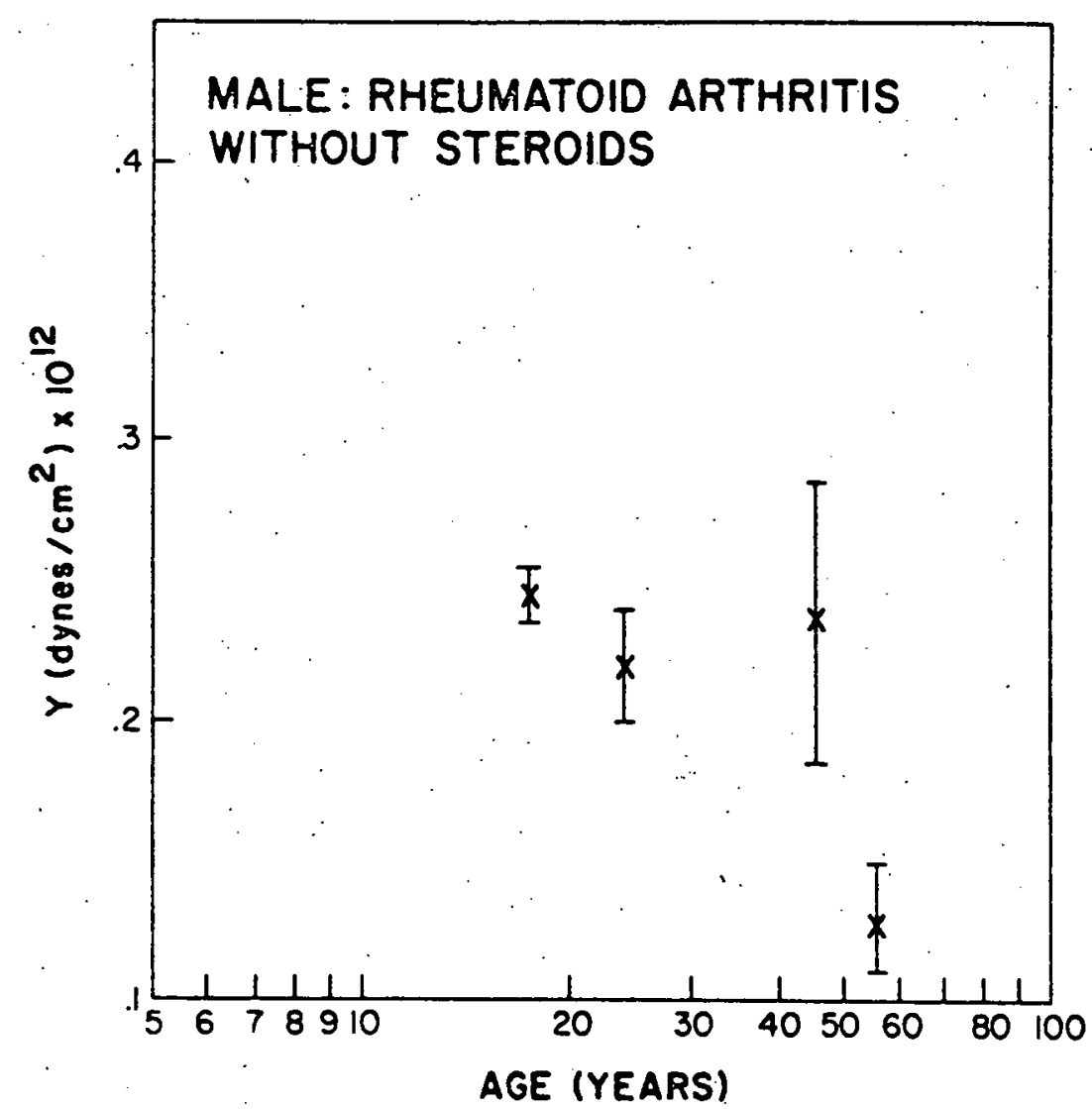

Fig 8: Y vs age for 17 males with rheumatold arthritis and no history of corticosteroid therapy.

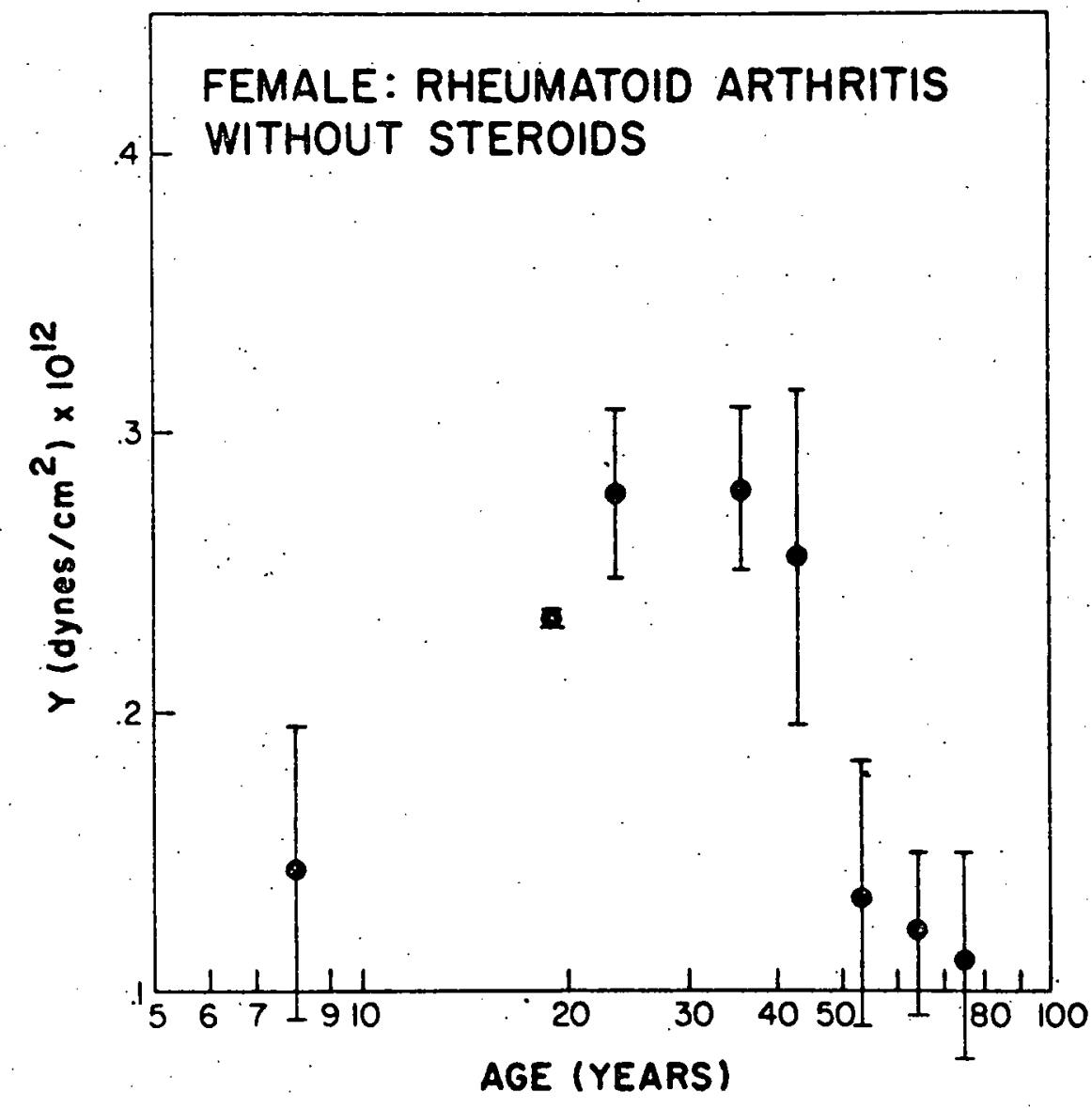

Fig 9: Y vs age for 39 rheumatold females without sterold therapy. 


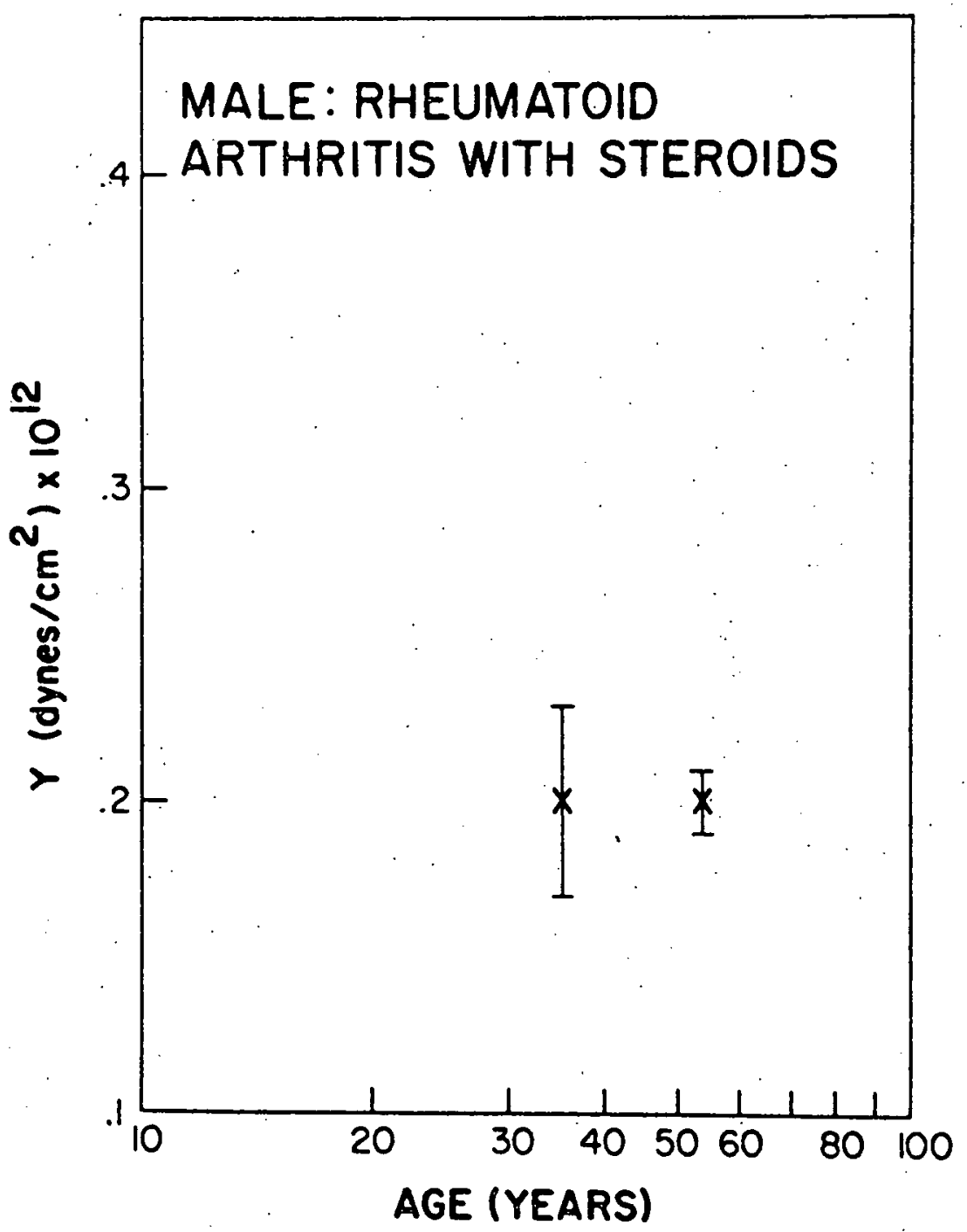

F1g 10: Y vs age for 11 rheumatold males with a history of sterold therapy.

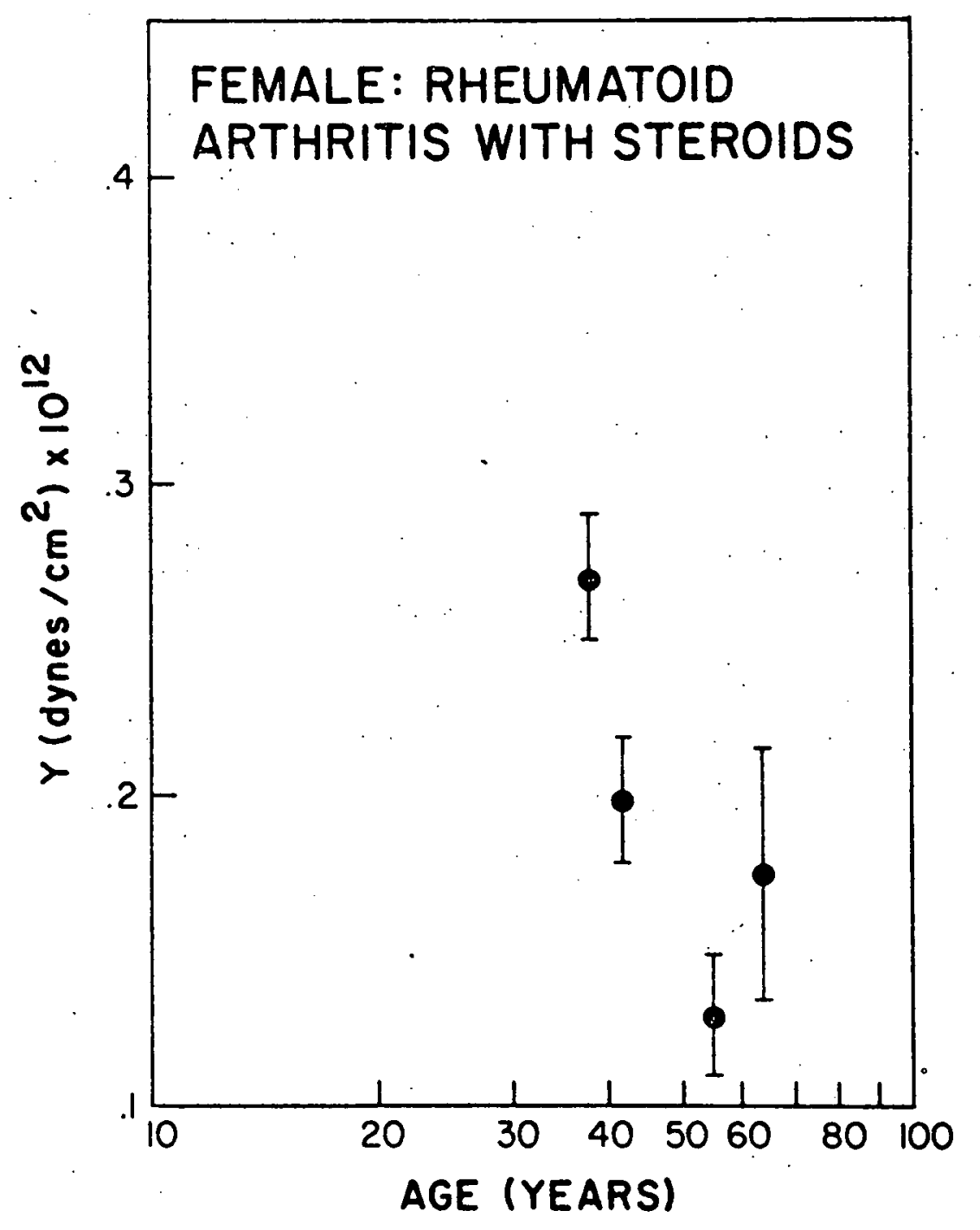

Fig 11: Y vs age for 34 rheumatold females with a history of steroid therapy. 


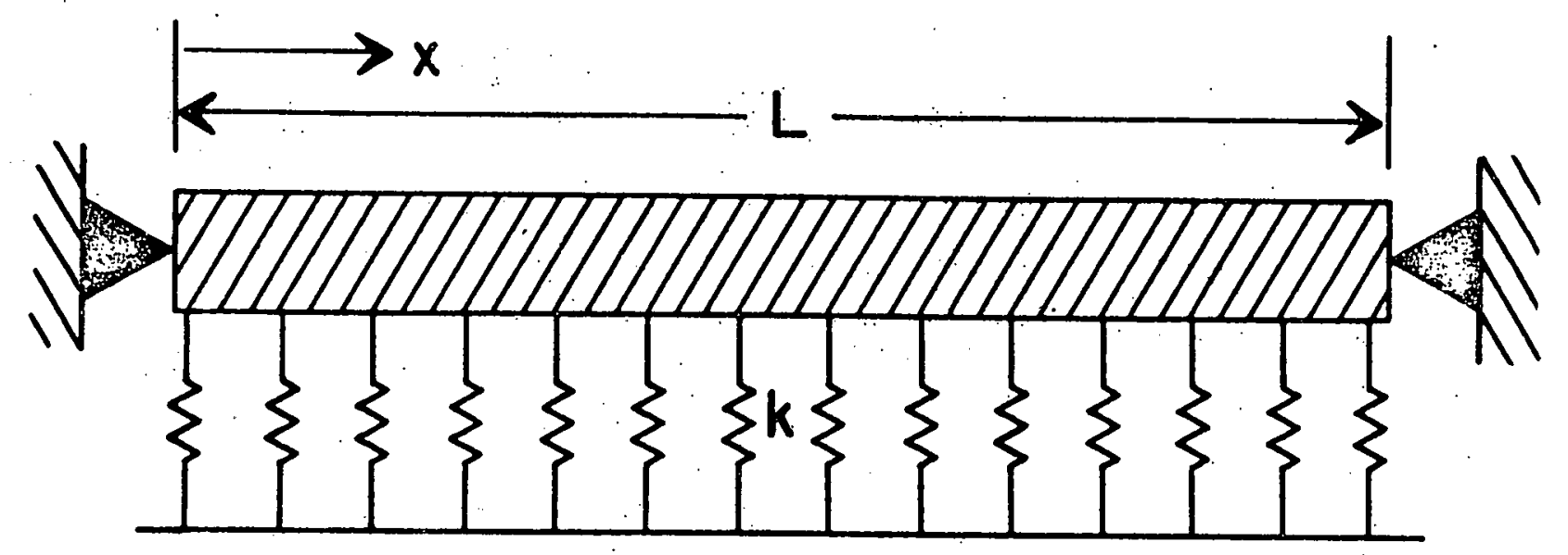

F1g 12: Model II boundary conditions.

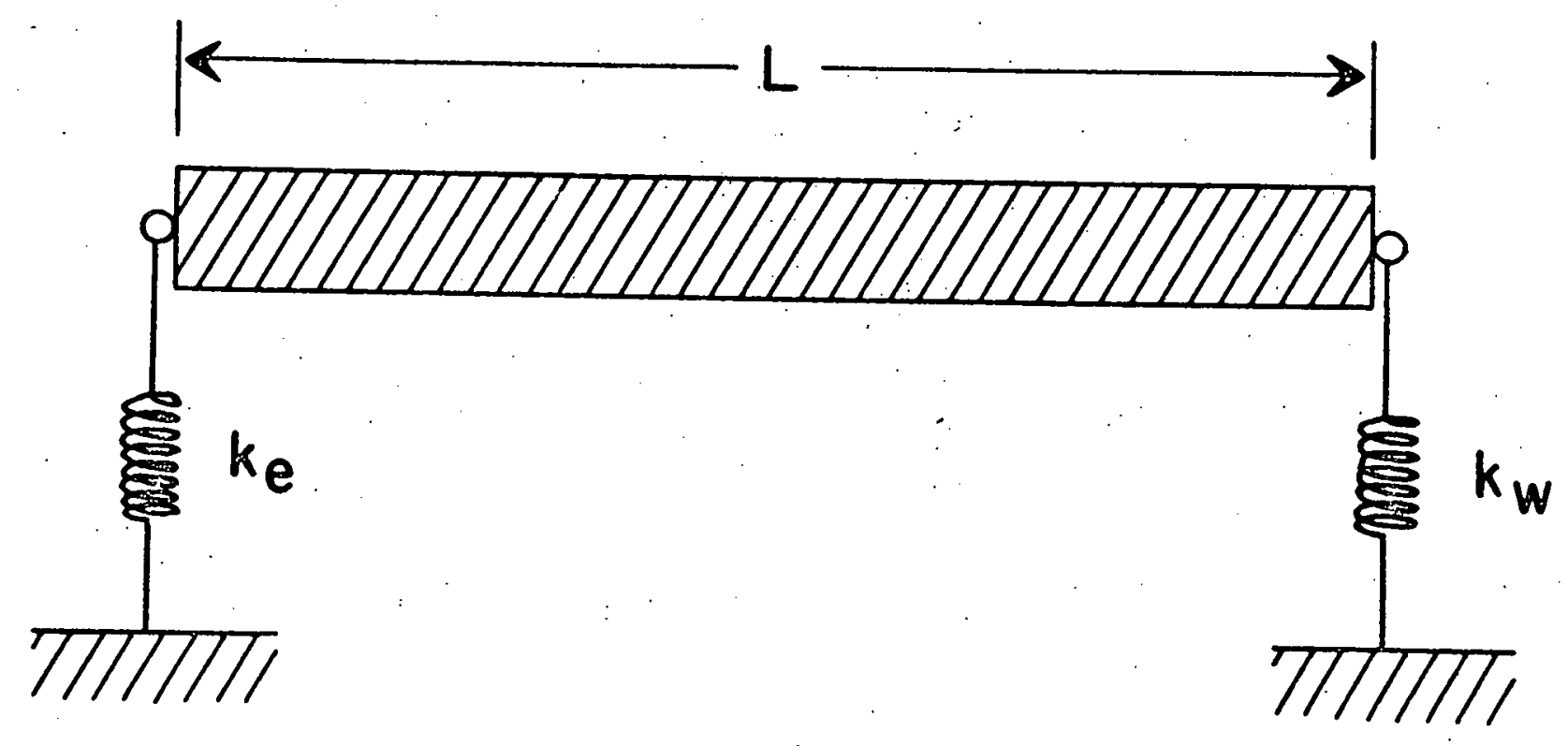

Fig 13: Model III boundary conditions. 


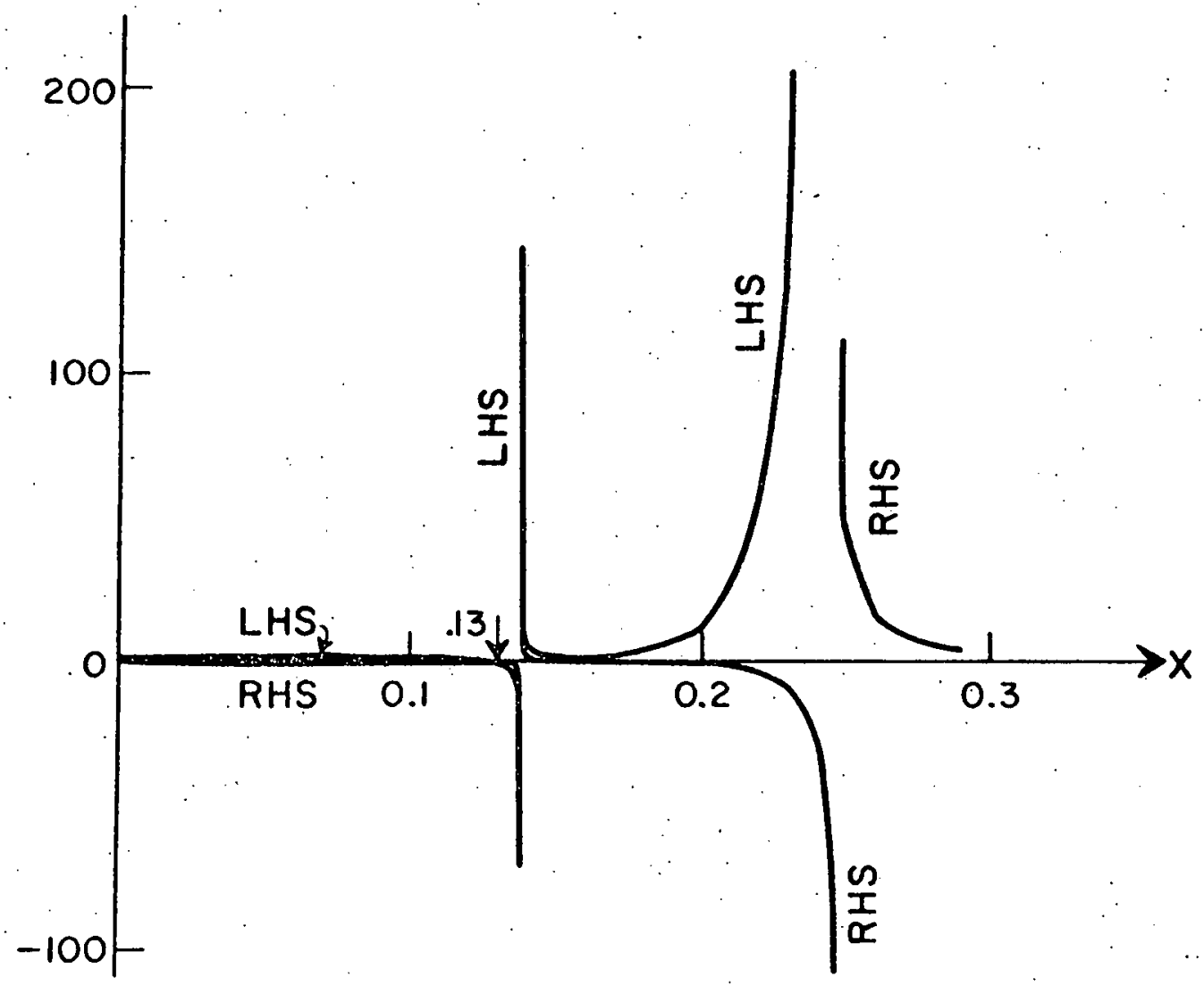

Fig 14: Typical plot of Equation 36. The fundamental resonance occurs at $\mathrm{X} \cong 0.13$. 


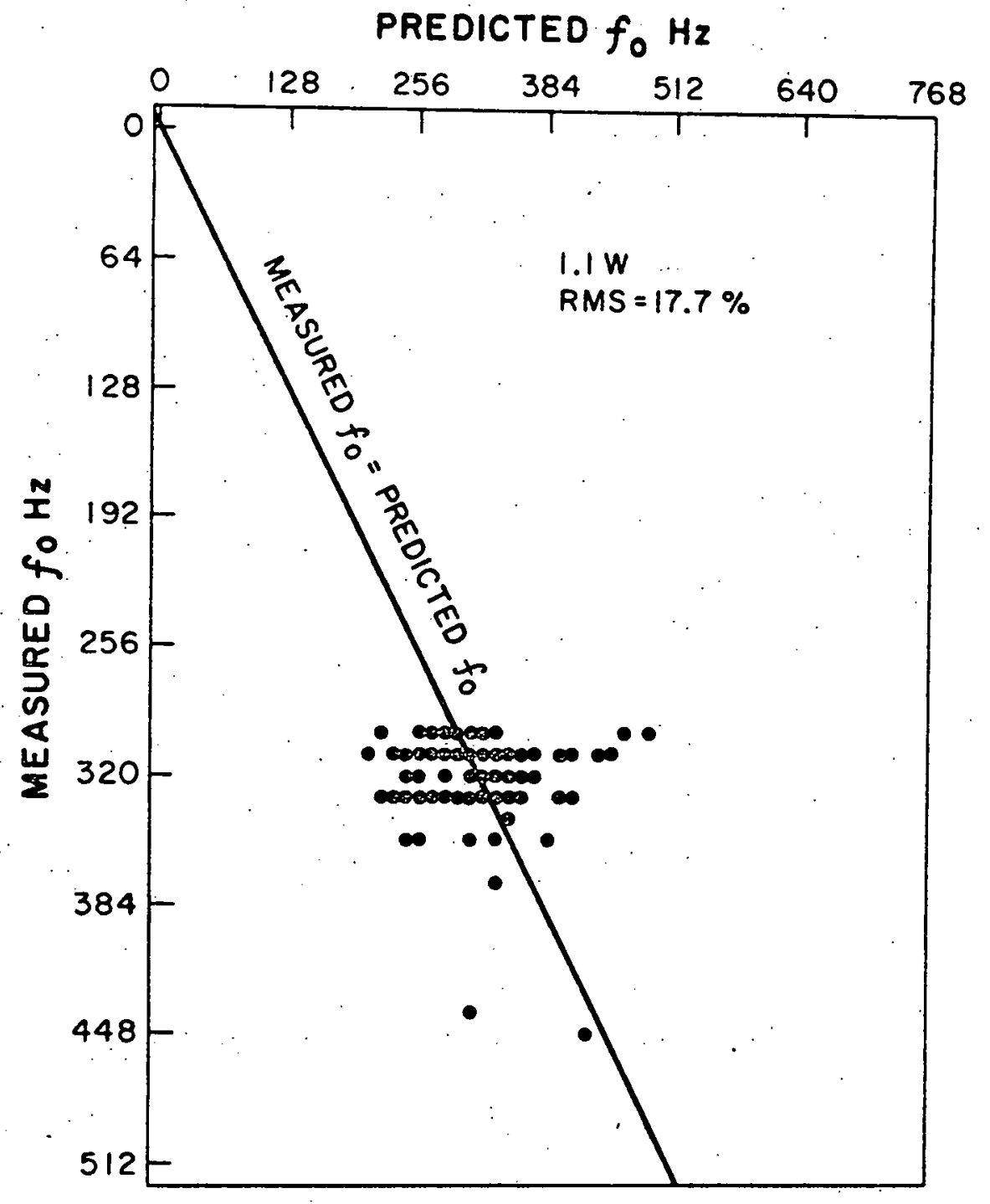

Fig 15: Predicted $f_{0}$ vs measured $f_{0}$ based on Model III for 118 schoolchildren. 1.1W was substituted for the measured value of $W$ in Equation 36 .

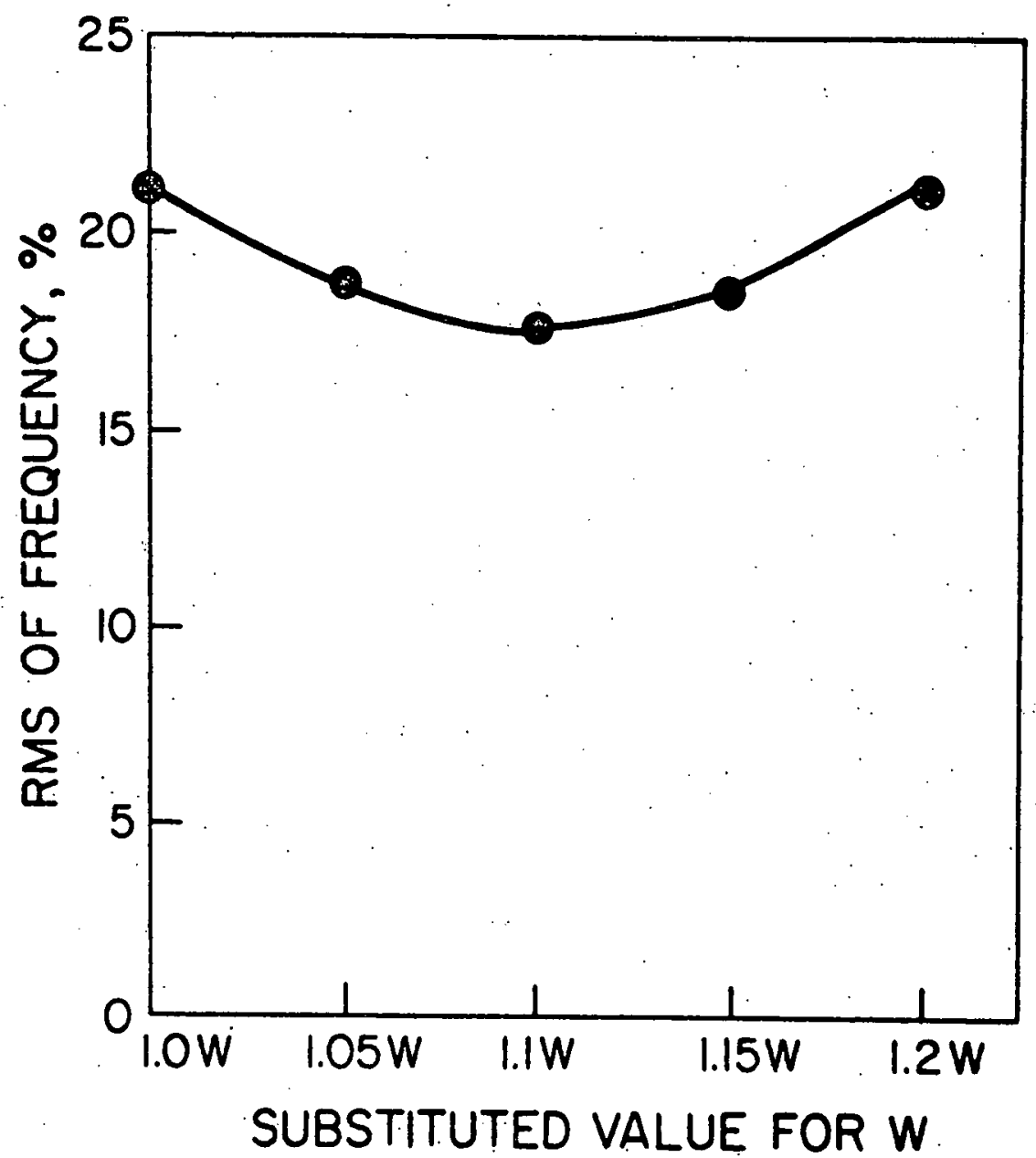

Fig 16: RMS vs substituted value for $W$ in Equation 36 for 118 schoolch1ldren. 